\title{
Surveillance of pediatric injury hospitalizations in Southern California
}

\author{
Phyllis F Agran, Diane G Winn, Craig L Anderson
}

\begin{abstract}
Objectives-This study was designed to determine the incidence and causes of injury hospitalizations/fatalities to children less than 15 years of age.
\end{abstract}

Setting-Central Orange County,
California.
California.

Design-Cases were identified through a population based hospital and coroner's office surveillance system.

Subjects - The sample consisted of children 0-14 years of age who were residents of the study area and sustained an injury between 1 January 1991 and 31 December 1992 resulting in hospitalization or death.

Results-Over the two year study period, 1361 children $0-14$ years of age were hospitalized or died as a result of injury. This represents a crude annual injury rate of $318 / 100000$ children. Rates were highest for children less than 5 years - this age group sustained the highest rate for eight of nine specific causes of injury. Falls were the leading cause of hospitalizations for all ages. Pedestrian injuries were more common among children $1-4$ years and 5-9 years, while bicycle injuries were more common among older children.

Conclusions-This study, one of the first population based studies in a Southern California urban/suburban community, found lower rates of injury hospitalization than studies conducted over a decade ago. These lower rates may reflect changes in hospitalization trends and/or injury prevention programs. Comparisons with more recent studies in inner city communities in the north east also show regional differences in rates and causes. Injury prevention efforts should particularly address the higher injury rates among children less than 5 years of age. This study also illustrates the need for regional and local data to guide injury control.

(Injury Prevention 1995; 1: 234-237)

Keywords: surveillance, injury hospitalizations.

Pediatric Injury Prevention Research Group, University of California, Irvine, USA

DG Winn

CL Anderson Correspondence to:
Dr Phyllis F Agran, Health Dr Phyllis F Agran,
Policy and Research, Policy and Research, University of Californi Irvine, CA 92717-4650, USA.

The probability of a child dying or becoming severely disabled from an injury exceeds that of all causes of childhood illness. Population based surveillance studies have revealed geographic, racial, ethnic, environmental, socioeconomic, and age related differences in the causes of injury deaths. ${ }^{1-3}$ In contrast to fatal injuries, there have been fewer studies of the causes and rates of non-fatal injuries among children. Most of the studies that have included emergency department and/or hospitalized children date back to the late 1970s and early $1980 s^{4-6}$ The leading causes of injury hospitalizations in these studies were falls, followed by being a motor vehicle occupant, sports, and cut or struck by machinery. Rates of hospitalization for injury for children less than 15 years ranged from 318 to $778 / 100000$ population.

Two recent studies that include fatal and non-fatal injuries demonstrate changing trends in causes and frequency of injury. Although falls remain the leading cause of injury, these studies found a substantial increase in intentional injuries. For example, the study of Schwarz et al in an urban African-American population found that interpersonal intentional injuries were increasingly prevalent and accounted for $58 \%$ of the total among children 10-19 years of age. Over the four year study period (1987-90), intentional firearms injury increased by over $200 \%{ }^{7}$ The northern Manhatten injury surveillance system of hospital admissions (1983-7) detected an increasing incidence of injury among children $5-16$ years of age, but a declining incidence among children less than 4 years. ${ }^{8}$ Gunshot wounds were a major cause of fatal injuries. These two studies were carried out in large inner cities in the eastern United States. However, there are no recent published non-fatal injury surveillance data for other areas of the country. The demographics, population mix, and environmental conditions in Southern California vary from other regions where pediatric injury surveillance has been conducted.

This study was designed to determine the incidence and causes of serious injury among children less than 15 years of age. The surveillance system included hospital admissions and fatalities in a south west US urban/suburban community in Orange County, California.

\section{Methods}

A population based hospital and coroner's officer surveillance system was established in central Orange County, California to identify children less than 15 years of age who sustained injuries resulting in hospitalization or death.

Ana, Anaheim, Fountain Valley, Garden Grove, Orange, Villa Park, and Tustin) and one census designated area (Tustin Foothills). The study population consisted of 213906 children age $0-14$ years of age; $49 \%$ were Hispanic, $37 \%$ non-Hispanic white, $12 \%$ 
Asian or Pacific Islander, $2 \%$ black, and less than $1 \%$ Native American or any other race. ${ }^{9}$ Twelve per cent had a family income less than the federal poverty level in 1990 .

Cases were defined as residents of the study area, $0-14$ years of age, who sustained an injury between 1 January 1991 and 31 December 1992 resulting in hospitalization or death. These cases were identified by daily monitoring of hospital admissions and a review of the log of deaths maintained by the county coroner's office. The medical record of each potential case was reviewed to verify that the admission was primarily the result of an injury and that the patient resided in the study area. Details of the injury and circumstances were then abstracted onto a standardized questionnaire.

Children were aggregated into the following vital statistics age groups: less than 1 year, 1-4 years, 5-9 years, and 10-14 years. Rates of injury were calculated as number of cases divided by the population reported in the $\mathbf{1 9 9 0}$ US census. Total rates, and rates by cause, age, and gender were calculated. Injury admissions included all blunt and penetrating trauma, burns, poisoning, immersions, aspirations, suffocations, and ingestions.

The eight hospitals included in the monitoring system were selected based on California hospital discharge data for 1988 to maximize ascertainment in the study area. ${ }^{10}$ These hospitals included two trauma centers, a university teaching hospital, and a children's hospital. Cases were also identified by periodic contact with two other trauma centers serving adjacent areas.

The comprehensiveness of the surveillance system was validated by examining 1991 California hospital discharge data for residents of the same geographic area. Discharges having an $\mathrm{E}$ code (cause of injury code) and a principal diagnosis of injury (ICD-N 800-995.89) or a V 71.4 code (observation following other accident) with an $\mathrm{E}$ code, were selected for this evaluation. ${ }^{10}$ Misadventures or complications due to surgical or medical care (E870-E879.9) and adverse effects of medications in therapeutic use (E930-E949.9) were excluded. ${ }^{11}$ Seven hundred ninety two injury discharges from 49 hospitals in six counties with home postal codes in the study area were identified. Six hundred forty two of these were from the monitored hospitals, indicating that the surveillance system identified $81 \%$ of the injury hospitalizations to children residing in the study area. Ninety one discharges $(12 \%)$ were from 21 other hospitals in Orange County and $59(7 \%)$ were from 20 hospitals in other California counties.

\section{Results}

Over the two year study period, 1361 children $0-14$ years of age were hospitalized or died as a result of an injury in the study population of 213906 . The total rates, and rates by age group by specific cause of injury, are presented in the figure and the table. The crude annual rate was $318 / 100000$ children. The age specific injury rates were highest for those less than 1 year and 1-4 years. The rates decreased with each successive age group such that the rate for those 10-14 years was less than one half that of the $1-4$ year olds. The rate for males $(403 / 100000)$ was almost twice that for females (229) 100000 ). Males sustained higher rates in each age group with the proportional difference less between boys and girls for children under 1 and 1-4 years.

Overall, falls were the leading cause of serious injury (resulting in hospitalization or death), with an annual rate of $105 / 100000$ children. Falls were also the leading cause among all age groups. The rate was highest for children 1-4 years (168/100 000) and infants $(155 / 100000)$, and decreased with increased age.

Transportation injuries that include pedestrian, bicyclist, and motor vehicle occupant, were the next most frequent cause of injury hospitalization and death. Pedestrian injury was the leading cause of transportation related injuries and the second leading cause of any injury (41/100 000). Similar to falls, children 1-4 years had the highest rate of pedestrian injuries followed by 5-9 year olds; a lower rate was found among those 10-14 years. Bicyclist injuries were the third leading cause, and were highest among the oldest age group. Motor vehicle occupant injury had the lowest rate of transportation related injuries and was highest among infants.
Annual rates per 100000 population (pop) of injury hospitalization/deaths to children $0-14$ years by cause and age in central Orange County, 1991-2 $(n=1361)$

\begin{tabular}{|c|c|c|c|c|c|c|c|c|c|c|}
\hline & \multicolumn{2}{|c|}{$\begin{array}{l}<1 \text { year } \\
\text { (pop 15 454) }\end{array}$} & \multicolumn{2}{|c|}{$\begin{array}{l}1-4 \text { years } \\
\text { (pop } 66556)\end{array}$} & \multicolumn{2}{|c|}{$\begin{array}{l}5-9 \text { years } \\
(\text { pop } 70680)\end{array}$} & \multicolumn{2}{|c|}{$\begin{array}{l}10-14 \text { years } \\
\text { (pop } 61216)\end{array}$} & \multicolumn{2}{|c|}{$\begin{array}{l}\text { All ages } \\
\text { (pop 213906 }\end{array}$} \\
\hline & $\overline{N o}$ & Rate & No & Rate & $\overline{N o}$ & Rate & $\overline{N o}$ & Rate & $\overline{N o}$ & Rate \\
\hline \multicolumn{11}{|l|}{ Cause } \\
\hline Falls & 48 & 155 & 223 & 168 & 111 & 79 & 68 & 56 & 450 & 105 \\
\hline Pedestrian & 5 & NA & 80 & 60 & 73 & 52 & 18 & 15 & 176 & 41 \\
\hline $\mathrm{Bic}$ & 0 & & 19 & 14 & 61 & 43 & 57 & 47 & 137 & 32 \\
\hline Poisc & 9 & $\mathrm{~N} f$ & 76 & 57 & 4 & NA & 16 & 13 & 105 & 25 \\
\hline Oc & 13 & 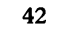 & 29 & 22 & 23 & 16 & 3 & 25 & 96 & 22 \\
\hline Ass & 17 & 5 & 27 & 2 & 4 & NA & 35 & 29 & 83 & 19 \\
\hline $\mathrm{Bu}$ & 17 & 5 & 35 & 2 & 10 & 7 & 4 & NA & 66 & 15 \\
\hline $\begin{array}{l}\text { Asphyxiation/ } \\
\text { aspiration/in }\end{array}$ & 20 & 65 & 29 & 22 & 11 & 8 & 3 & NA & 63 & 15 \\
\hline Immersion & 4 & $N$ & 45 & 34 & 7 & NA & 1 & $\mathbf{N}$ & 57 & 13 \\
\hline Other & 6 & & 50 & 38 & 30 & 21 & 42 & 3 & 128 & 30 \\
\hline All causes & 139 & 450 & 613 & 461 & 334 & 236 & 275 & 225 & 1361 & 318 \\
\hline \multicolumn{11}{|l|}{ Gender } \\
\hline Male & 81 & 50 & 30 & 558 & 232 & 320 & 191 & 303 & 886 & 403 \\
\hline Female & 58 & 387 & 231 & 357 & 102 & 148 & 84 & 142 & 475 & 229 \\
\hline
\end{tabular}

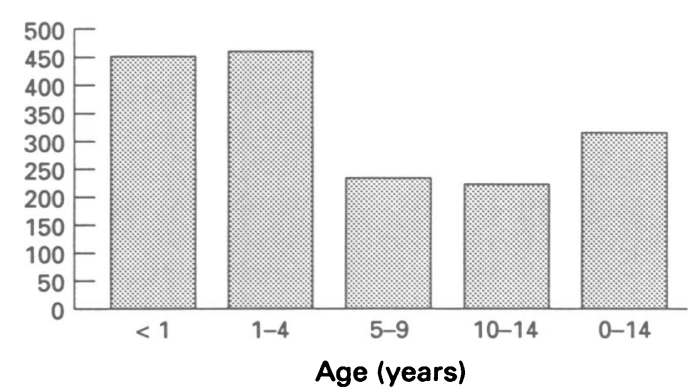

Annual rates per 100000 population of injury

hospitalizations/deaths to children $0-14$ years by age in central Orange County, 1991-2 $(n=1361)$. 
The rates of poisonings were bimodal, with the highest rate among those 1-4 years (57/ 100000 ) and a second, but lower rate for 10-14 year olds (13/100 000). Poisonings among the younger children were primarily unintentional ingestions, whereas, most were suicide attempts among the older children.

Assaults were highest among infants (55/ 100000 ), followed by $10-14$ year olds (29/ 100000 ), and infrequent among those 5-9 years. Similarly burns, and asphyxiations/ aspirations/foreign body ingestions were highest among infants (55/100000 and 65/ 100000 respectively) with a marked drop-off among those 1-4 years (26/100 000 and 22/ 100000 ) and a very low rate among older children.

The rate of water immersions was the lowest for the causes studied (13/100000) and were primarily found among 1-4 year olds (34/ 100000 ). Eighty one per cent occurred in residential pools/spas.

\section{Discussion}

This population based study in a large urban/ suburban community in Southern California found an annual rate of injury hospitalization/ death of 318/100 000 for children 0-14 years of age. Toddlers and preschool age children (1-4 years of age) had the highest rate, 461/100 000, followed by infants (less than 1 year of age), $450 / 100000$. These rates are much lower than those reported in studies from the 1970s and early 1980 s. $^{45}$ Factors that may contribute to the lower rates found in our study include: (1) changes in hospitalization trends; (2) effects of injury intervention efforts; and (3) differences in the demographic characteristics of the study communities. ${ }^{12}$

The rates reported in a recent study in northern Manhattan, New York were considerably higher than those in our study. ${ }^{8}$ The New York study included an estimate of the missing cases not identified through the hospital surveillance, whereas our rates were based on actual cases identified through our surveillance that captured only $81 \%$ of the hospital discharges. However, even if we adjusted our rates to reflect the $19 \%$ missed cases, our rates remain lower, perhaps reflecting environmental and demographic differences between inner city populations and our urban/suburban community.

Despite differences in the database used, age range, grouping of cases and demographics, one striking similarity in all these studies is that falls are the leading cause of injury across all age groups. This is not surprising considering the diverse nature of falls and the age related differences in types of falls. In our study, infants fell from furniture and household objects; more toddlers fell out of windows and off balconies, and, older children fell off playground equipment or in sports related activities. Furthermore, there are few measures to prevent the majority of falls.

Transportation related injuries and, in particular, pedestrian injuries, were the second leading cause in this study. In contrast to other studies, especially those based on police data, this database demonstrated that the pedestrian injury rate among those 1-4 years was higher than among school age children, 5-9 years. The impact of non-traffic related pedestrian events in the younger age group, for example those occurring in residential driveways, becomes apparent in hospital based surveillance. ${ }^{13}$ While pedestrian injury rates decreased with increasing age, bicyclist injury rates increased. This may reflect the increased exposure as children become older and ride bicycles. Occupant injury rates were the lowest of the transportation related causes of injury.

There has been a shift from the predominance of motor vehicle occupant injuries of the early 1980 s to other types of injuries. ${ }^{14}$ The higher proportion of occupant injuries in our study compared with previous studies may relate to increased exposure as public transportation in this Southern California community is relatively poor and the private motor vehicle is the primary mode of transportation.

The motor vehicle occupant injury rate was highest among infants. This may, in part, reflect an increased propensity to hospitalize infants because they are non-verbal and unable to complain of pain. Alternatively, similar to other studies, the infant rate of occupant injury may reflect the fact that child restraint system use among infants and toddlers is decreasing, while other age groups continue to have increasing restraint use. ${ }^{15}$

Studies in both New York and Philadelphia had much higher rates of violent/assaultive injuries than we found in Southern California. Fifty eight per cent of the injuries among 10-19 year olds in Philadelphia were in this category and $9 \%$ of the injury hospitalizations in New York were for assaults. ${ }^{78}$ Gunshot wounds were a major cause of fatal injuries to children in the New York study. ${ }^{7}$ Both of these studies included youth over 15 years of age in contrast to ours that included only children through 14 years of age. Thus the age groups and/or demographics may account for these regional differences. The highest rate of assault injuries in our study, however, was among infants, indicating that child abuse accounts for a large proportion of non-fatal as well as fatal injuries in children less than 1 year. ${ }^{16}$

Despite major prevention efforts (for example childproof caps), poisoning, particularly among 1-4 year olds, still remains a leading cause of hospitalization. Other leading causes of injury hospitalizations in our study population, especially among those less than 1 year, were burns and foreign body ingestions. The greater proportion of immersions in our study, compared with others, related to the prevalence of residential pools/spas in both private homes and high density rental units in Southern California.

This study also illustrates age related differences in leading causes of injury. Children less than 5 years had the highest rate of injury for eight of the nine causes of injury studied. Infants, non-verbal and dependent on their caregivers to meet their needs, were at increased risk for motor vehicle occupant 
injuries, assaults, burns and asphyxiations/ aspirations/foreign body ingestions. Children aged 1-4 had the highest rates of pedestrian injuries, poisonings, falls, and immersions. Both the higher total rates, and the diversity of causes of injury among the toddlers and preschool age children exemplifies that this period of growth and development is at high risk for injury. The curious and exploratory $1-4$ year old frequently has the motor skills to 'access' the hazardous situation, but lacks the perceptual and cognitive skills to avoid the injury. Only bicycle related injuries were higher among the 10-14 year olds, who have the increased freedom and ability to ride bicycles along with the shift towards the risk taking behavior of adolescence. These results confirm that the developmental characteristics of children as they relate to injury should be a focus of anticipatory guidance and considered in all injury prevention activities.

\section{Conclusion}

To our knowledge, this is the only recent US population based study of pediatric injuries not conducted in a north east inner city population. Compared with other studies, overall rates of injury hospitalization were lower in this Southern California urban/suburban community. The lower overall rates compared with studies conducted over a decade ago may reflect changes in hospitalization trends and/or injury prevention programs, while the lower rates and the differences in leading causes of injury compared with the more recent inner city studies may in part be due to differences in housing, transportation, climate, other environmental factors and demographics, as well as differences in the age groups studied. However, similar to these other studies, falls and pedestrian injuries were leading causes of injury hospitalization among children in this study population. The extent of the continuing threat of these injuries to the health and well being of children indicate that new approaches must be considered in preventing injuries such as these which have no effective single means of prevention. The findings of higher injury rates among children under 5 years of age also illustrates the need to have injury prevention efforts particularly address this high risk group. This study confirms the fact the local, regional, and age specific injury data are needed for focus and guide appropriate intervention activities, both programmatic and public policy.

This research was supported by grant number R49-CCR904406 from the Centers for Disease Control and Prevention. The contents are solely the responsibility of the authors and do not necessarily represent the official views of the Centers for Injury Control and Prevention.

1 Baker SP, O'Neill B, Ginsberg MJ, Li G. The injury fact book. 2nd Ed. New York: Oxford University Press, 1992. 2 Waller AE, Baker SP, Szocka A. Childhood injury deaths: national analysis and geographic variations. Am $\mathcal{F}$ Public Health 1989; 79: 310-5.

3 Guyer B, Ellers B. Childhood injuries in the United States. Am F Dis Child 1990; 144: 649-52.

4 Gallagher SS, Finison K, Guyer B, Goodenough S. The incidence of injuries among 87000 Massachusetts childincidence of injuries among 87000 Massachusetts children and adolescents: results of the $1980-81$ statewide childhood injury prevention program survel
system. Am $\mathcal{f}$ Public Health 1984; 74: 1340-7.

5 Fife D, Barancik JI, Chatterjee BF. Northeastern Ohio trauma study: II. Injury rates by age, sex, and cause. $A m \mathcal{F}$ Public Health 1984; 74: 473-8.

6 Runyan CW, Kotch JB, Margolis LH, Buescher PA. Childhood injuries in North Carolina: a statewide analysis of hospitalizations and deaths. Am $\mathcal{F}$ Public Health 1985; 75: 1429-32.

7 Schwartz DF, Grisso JA, Miles CG, Holmes JH, Wishmer $A R$, Sutton RL. A longitudinal study of injury morbidity in an African-American population. $¥ A M A 1994 ; 271$ : $755-60$.

8 Davidson LL, Durkin MS, O'Connor P, Barlow $H$, Heagarty MC. The epidemiology of severe injuries to children in northern Manhattan: methods and incidence children in northern Manhattan: methods and incide

9 Bureau of Census. 1990 Census of population and housing. Washington, DC: Bureau of Census, US Department of Commerce, 1993.

10 Office of Statewide Health Planning and Development. Hospital discharge file. Sacramento, CA: Office of Statewide Health Planning and Development, State of California, Health and Welfare Agency, 1991.

11 World Health Organization. International classification of diseases. 9th Revision. Clinical modification. 3rd Ed. Washington DC: Department of Health and Human Services, Public Health Service, Health Care Financing Administration, 1989.

12 Marganitt B, MacKenzie EJ, Deshpande JK, Ranzy AI, Haller JA. Hospitalizations for traumatic injuries among children in Maryland: trends in incidence and severity, children in Maryland: trends in incidence and se

13 Agran PF, Castillo DN, Winn DG. Limitations of data compiled from police reports pediatric pedestrian and compiled from police reports pediatric pedestrian and
bicycle vehicle events. Accid Anal Prev 1990; 22:361-70.

14 Anonymous. Deaths resulting from firearm and motor vehicle-related injuries - United States, 1968-1991. MMWR Morb Mortal Wkly Rep 1994; 43(3): 37-42.

15 Betancourt R. The California Office of Traffic Safety seat belt survey. Fresno: California State University at Fresno, 1995.

16 Emergency Preparedness and Injury Control (EPIC) Branch, California Department of Health Services. Injuries in California 1991. Sacramento, CA: EPIC Branch, California Department of Health Services, March 1994. 